\title{
Pancreatic mesenchymal stromal cells: Characteristics and possible origin
}

\author{
Sara M. Ahmed and Nagwa El-Badri* \\ Center of Excellence of Stem Cell, Zewail City of Science and Technology, Cairo, Egypt
}

\begin{abstract}
Mesenchymal stromal cells (MSCs) are heterogeneous group of cells with multipotent capability that were primarily isolated from bone marrow. Many reports suggest that MSCs reside in almost all tissues and organs. Pancreatic stem cells are of great clinical interest due to their potential role in treatment of diabetes mellitus (DM). MSCs were isolated from both adult and fetal pancreatic tissues. These cells resemble bone marrow MSCs regarding their surface markers expression and mesodermal differentiation potential. Pancreatic MSCs are also able to differentiate into pancreatic endocrine lineage cells, suggesting a possible source for cell replacement therapy for DM. In this review, we will discuss the characterization of pancreatic MSCs, their possible origin and their use as cell therapy for diabetes.
\end{abstract}

\section{Introduction}

Mesenchymal stromal cells (MSCs) are heterogeneous population of cells that were primarily isolated from the bone marrow [1]. MSC-like cells have been isolated from other tissues like the human placenta [2], peripheral blood [3], umbilical cord [4], adipose tissue [5], endometrium [6] and pancreas [7,8]. According to the definition of the International Society for Cell Therapy, MSCs are characterized by being plastic-adherent in standard culture condition and can be differentiated in vitro into osteoblasts, chondroblasts and adipocytes [9-11]. They express certain surface markers such as CD105, CD90, CD73, while lack the expression of CD45, CD34, CD14, CD11b, CD79 alpha, CD19 and HLA-DR. Animal experiments showed that MSCs could engraft into wounds, and contribute to remodeling of injured tissues $[10,11]$. MSC transplantation has shown promising results in treatment of diseases such as diabetes [12-14], autoimmune diseases [15-17], brain repair [18,19], and blood malignancies [20,21]

In this review, we will examine the characteristics of pancreatic MSCs, their possible origin and their role in cell replacement therapy for diabetes.

\section{Characteristics and origin of pancreatic MSCs}

\section{MSCs isolated from exocrine pancreatic culture}

MSCs were isolated from exocrine tissue culture (culture that includes both acinar and duct epithelial cells [7,8,22-24]. They resembled bone marrow MSCs both morphologically and in their capability to differentiate into osteoblasts, adipocytes and chondroblasts [7,8,22,23]. Interestingly, pancreatic MSCs isolated from exocrine pancreatic cultures were also shown to generate pancreatic endocrine progenitors. Upon expansion of MSCs isolated from exocrine pancreatic tissues, they expressed endocrine progenitor markers such as Is11, Nkx2.2, Nkx6.1, nestin, Ngn3, PDX1, and NeuroD [8]. Likewise, MSCs isolated from pancreatic duct tissue cultures expressed pancreatic endocrine progenitor markers such as PAX4 and Ngn3, when induced to differentiate into cells of endocrine lineage [7].

\section{Origin of MSCs isolated from pancreatic exocrine tissue culture}

As bone marrow MSCs- like cells have been isolated from different tissues, it was hypothesized that organ MSCs may represent a population of migrating bone marrow MSCs, that "home" to the pancreas [25,26]. In support of this hypothesis, tracking bone marrow MSCs has shown that they populate the pancreatic tissue, and that pancreatic MSCs found in culture were shown to be derived from marrow MSCs [23,27]. A contradictory proposal was suggested by Lechner et al. [28] who showed that bone marrow do not contribute to pancreatic regeneration nor turnover [28]. This was proven through transplantation of green fluorescent protein positive (GFP), sex-mismatched bone marrow into mice. while blood cells acquired full donor chimerism, however, examination of more than $100,000 \beta$-cells showed no GFP positive $\beta$-cells [28].

Epithelial to mesenchymal transition process(EMT) was suggested as a possible mechanism of generation of mesenchymal stem cells from cultured exocrine acinar and duct cells $[22,24,29$,$] . EMT is a process in$ which epithelial cells change their phenotype to become mesenchymal cells [30,31]. For this change to occur, epithelial cells lose many of their specific structures and functions, such as cell-cell contact and their cellular polarity while gain the ability to migrate and invade the surrounding tissues.

For EMT process to happen, certain cellular changes should occur. First, a change in the epithelial cell shape due to loss of cellular polarity; epithelial cells become spindle in shape. This change in the shape is mediated by the decrease in the expression of the adhesion molecules

Correspondence to: Nagwa El-Badri, M.D., Ph.D, Director, Center of Excellence of Stem Cells, Zewail City of Science and Technology, Cairo, Egypt, Tel: +20 2 38540 401; E-mail: nelbadri@zewailcity.edu.eg

Key words: beta cells, endocrine, exocrine, mesenchymal stromal cells, mesenchymal stem cells, pancreas

Received: October 22, 2016; Accepted: December 15, 2016; Published: December 19, 2016 
between epithelial cells- mainly E-cadherin. Second, a change in markers expression; an increase in the mesenchymal markers such as vimentin, alpha smooth muscle actin, N-cadherin; and a decrease in epithelial markers such as E-cadherin. Third, upregulation of important EMT transcription factors such as Snail and Slug occurs(reviewed by Thiery et al. [32]). These cellular changes occur under the influence of a network of signals of growth factors, mainly TGF $\beta$, via signaling pathway such as Wnt and Notch pathway and transcription factors such as Snail family (Snail and Slug), Twist, ZEB1 and 2 (reviewed by Thiery et al. [32] ).

Lima et al. [24] reported that EMT occurs in cultured exocrine cells giving rise to mesenchymal stromal- like cells. Cultured exocrine cells gradually became spindle shaped, losing exocrine markers (amylase and CK19), and epithelial markers (E-cadherin). Meanwhile, mesenchymal markers such as vimentin and $\alpha$-SMA were upregulated. Cells expressing both exocrine and mesenchymal markers have been detected as well. Interestingly, the EMT transcription factor Snail2 was upregulated in these exocrine-derived mesenchymal cells [24]. Mesenchymal cells derived from the dedifferentiated exocrine cells were characterized as MSCs, as they expressed markers of MSCs and showed the ability to differentiate into cells of mesodermal lineages (adipose tissue, bone and cartilage). Genetic lineage tracing was used to determine the source of these MSCs in exocrine culture. It showed that pancreatic acinar cells gave rise to MSCs, plausibly via the process of EMT [24] (Table 1).

In another study by DeWaele et al. [29], TGF $\beta$ and Activin were suggested to underlie EMT-induced cellular changes in cultured human exocrine cells. Interestingly, suppression of EMT pathway enhanced the reprogramming of these MSCs into insulin-producing cells. These cells have the capability of insulin secretion in vitro and in vivo, when injected into streptozotocin diabetic NOD/SCID mice [24].

A recent study of Corritore et al. [22], in which the human pancreatic duct marker, CA19-9, was used to isolate pancreatic duct epithelial cells, has demonstrated that the isolated CA19-9+ $9^{+}$cells acquired mesenchymal phenotype via EMT. With the exception of CK19 and SOX9 duct markers, there has been downregulation of other duct epithelial markers such as E-cadherin, CD133, HNF1b, carbonic anhydrase II and in the CA19-9+ duct cells [22]. As duct markers expression decreased, mesenchymal markers such as vimentin and $\alpha$-SMA gradually increased. Switch from E-cadherin into $\mathrm{N}$-cadherin was also observed. These cellular changes were accompanied by upregulation of the EMT marker Snaill. Upon inhibition of EMT with the TGF $\beta$ signaling inhibitor, A83-01, no such cellular changes were noticed in cultured CA19-9 $9^{+}$duct cells, providing an evidence for the generation of mesenchymal cells from CA19-9+ duct cells via an EMT process (Table 1).

\section{MSCs isolated from pancreatic endocrine (islet) culture}

MSCs were isolated from adult and fetal pancreatic islets [33-35]. Highly proliferative MSCs were also isolated from human fetal islets $[33,34]$. These cells were positive for the stem cell markers nestin and ABCG2 and showed the expression of pancreatic islets hormones such as insulin, glucagon in serum free media [33]. Isl-1 and nestin-positive MSCs were also isolated from adult pancreatic islets. These MSCs could be differentiated into pancreatic endocrine lineage cells, expressing pancreatic endocrine markers Ipf-1, Isl-1, Ngn-3, Pax4, Pax6, Nkx2.2, and Nkx6.1, in addition to pancreatic endocrine hormones such as insulin, glucagon, and somatostatin. They also capable of differentiation into albumin producing cells upon transplantation into SCID mouse liver [35].

MSCs-like islet precursors generated from dedifferentiated human islet epithelial cells were reported by Gershengorn et al. [36], and termed human islet precursor cells (hIPCs). During expansion in serum-containing media, islet epithelial cells gradually acquired the mesenchymal phenotype, producing hIPCs. Islet epithelial cells showed gradual decrease in the epithelial as well as endocrine lineage markers, and increase in mesenchymal markers. Upon serum deprivation, the resulting mesenchymal cells (hIPCs) gradually acquired the epithelial and endocrine phenotype forming aggregates or clusters. When these clusters were transplanted into mice under the kidney capsule, they matured into insulin-secreting cells [36].

Similarly, dedifferentiation of human fetal insulin-secreting cells cultured in serum-containing medium into MSCs-like cells has been reported [37]. Human fetal insulin-secreting cells gradually acquired fibroblast-like phenotype, and showed increase in the mesenchymal markers (such as vimentin, $\alpha$-SMA, CD44 and CD90) and decrease in the endocrine, duct and exocrine epithelial markers (such as insulin, glucagon, somatostatin, pancreatic polypeptides, CK19, CK7 and amylase) [37].

Several research teams have characterized hIPCs that exhibit characteristics of conventional MSCs [38-40]. They adhered to plastic, and expressed MSC markers, such as CD105, CD90, CD73, CD44, CD29, and CD13 in addition to nestin and vimentin. Pericyte markers like CD146, NG2, $\alpha$-SMA and PDGF-R $\beta$ were also expressed. On the other hand, these MSC-like cells were negative for hematopoietic and endothelial markers, such as CD31, CD34 and CD45, and for pancreatic duct markers, CK19 and CA19.9. When induced to differentiate under in vitro culture conditions, hIPCs showed multipotency as they differentiated into cells of osteogenic, chondrogenic and adipogenic lineages. When cultured in serum-free media, hIPCs formed clusters that express insulin, glucagon, and somatostatin [38-40].

\section{Origin of MSCs isolated from pancreatic endocrine tissue culture}

The generation of hIPCs through dedifferentiation of islet epithelial cells, primarily reported by Gershengorn et al. [36]; was attributed to an EMT process. During culture in serum-containing media, islet cells acquired a fibroblast-like morphology, gradually losing epithelial marker transcripts (such as E-cadherin, claudin-3, claudin- 4 and PECAM-1), as well as endocrine marker transcripts (such as PDX1 and proinsulin). Meanwhile, the mesenchymal marker transcripts (such as vimentin, nestin, $\alpha$-SMA and matrix metalloproteinase 2) were all increased. By immunostaining, hIPCs showed filamentous expression of vimentin and nestin; a pattern that was similar to that of mesenchymal cells.

Table 1. Summary of the possible origin of pancreatic MSCs.

\begin{tabular}{|c|c|c|c|}
\hline Source of Pancreatic MSCs & Possible Origin of Isolated MSCs & Species & References \\
\hline \multirow[t]{2}{*}{ Pancreatic exocrine tissue culture. } & EMT of pancreatic acinar epithelial cells & \multirow[t]{3}{*}{ Human } & {$[24,29]$} \\
\hline & EMT of pancreatic duct epithelial cells & & [22] \\
\hline \multirow{2}{*}{ Pancreatic endocrine tissue culture. } & EMT of $\beta$ cells of pancreatic islets & & {$[36,43]$} \\
\hline & Not yet specified, but may be resident pancreatic MSCs & Murine & [44-46] \\
\hline
\end{tabular}


Mesenchymal cells co-expressing epithelial and mesenchymal markers were also observed, suggesting that these cells were in a transitional stage. Most interestingly, the EMT main transcriptional regulators Snail1 and Snail2 were expressed in islet epithelial cells undergoing transition to mesenchymal cells, suggesting that EMT process may be responsible for these cellular changes. Even after dedifferentiation of islet epithelial cells to hIPCs, proinsulin transcripts were still detected and it was concluded that hIPCs originated from $\beta$ cells through EMT.

The process of EMT was reversed in serum-free media. Mesenchymal-like hIPCs underwent mesenchymal to epithelial transition (MET) in which hIPCs expression of epithelial and endocrine markers started to increase gradually while the expression of mesenchymal markers decreased [36].

Although MSC-like hIPCs, may have originated from $\beta$ cells by an EMT process, there was also a possibility that these cells represented a population of pancreatic MSCs, contaminating islet culture [38-40]. Hence, it was a necessity to conduct lineage tracing studies to track the fate of $\beta$ cells in pancreatic islets culture.

Lineage tracing studies conducted on human islets has shown that that $\beta$ cells undergo dedifferentiation and EMT in culture $[41,42]$. In a recent study [43], Lineage tracing analysis provided further evidence, as the cultured $\beta$ cells exhibited fibroblast- like morphology and ability to differentiate into cells of mesodermal lineages. These changes were mediated via EMT of cultured $\beta$ cells [43].

In contrary to results obtained from human islet culture, a series of lineage tracing studies provided evidence against the proposed model of $\beta$ cells dedifferentiation into mesenchymal cells or the occurrence of EMT [44-46]. However species difference maybe the cause of discrepancies between results of human and mice islet cultures (Table 1).

Type I diabetes resulted from autoimmune destruction of the pancreatic islets. Replacement of the these islets by islet transplantation was considered the best way to restore blood insulin level. However, the need of large number of donors islets is the greatest limitation for islet transplantation [47]. The ability of human $\beta$ cells to expand in vitro from limited number of islets giving rise to insulin producing cells through dedifferentiation/ redifferentiation process, may be considered a reliable way for increasing cell availability for cell replacement therapy of diabetes [48]. Through the inhibition of Slug, the EMT transcription factor expressed in the dedifferentiated human $\beta$ cells, researchers were able to increase insulin content of the dedifferentiated cells. Since it has shown that it disturb hormone expression in immortalized endocrine cell line $[48,49]$.

\section{Future perspective}

In this review, we discussed the characteristics of MSCs isolated from pancreatic tissues. The differentiation potential and origin of these MSCs is yet to be further investigated.

The process of EMT plays a major role during regeneration of different tissues. Despite the paucity of data on the mechanism of pancreatic regeneration, recent studies showing that pancreatic epithelial cells undergo an EMT- like process in culture provides evidence to the plasticity of the pancreatic epithelial tissue, and suggests a role for this plasticity in pancreatic regeneration. Few studies showed that EMT- derived cells from pancreatic acinar cells express MSC characteristics. Still, the EMT mechanism by which these MSCs are generated, and the conditions that favor their growth and expansion need further investigations.
In endocrine pancreatic tissue cultures, available data supports that differences exist between human and murine islet cells, whereas the evidence for an EMT process as an origin of MSCs in human islet culture is just being explored. In view of new data that MSCs arising in human endocrine culture express EMT markers Snail1 and Snail2 [50], designing experiments in which the role of EMT is directly explored in generation of MSCs in islet culture is fundamental for further understanding of islet biology.

New studies are also needed to address the issue of plasticity of EMT-derived mesenchymal cells in endocrine and exocrine pancreatic cultures. Since the ability of these cells to differentiate into pancreatic and extra-pancreatic lineages needs further investigation.

The role of EMT process has been critical during tissue repair by fibrosis. Fibroblasts, which have mesenchymal markers and origin, are generated during fibrosis by an EMT process. Although they share several properties with MSCs, such as the spindle shape, and expression the alpha smooth muscle actin and vimentin, they lack the multipotency of MSCs, and the mesodermal differentiation potency $[51,52]$. It is thus essential to properly characterize the pluripotency of EMT derived mesenchymal cells.

\section{Authors' contributions}

Authors contributed equally for this work.

\section{Acknowledgement}

This work has been supported by grant \# 5300 from the Science and Technology Development Fund.

\section{Financial disclosure}

This work has been supported by grant \# 5300 from the Science and Technology Development Fund.

\section{Competing interest}

No competing financial interests exist.

\section{References}

1. Pittenger MF, Mackay AM, Beck SC, Jaiswal RK, Douglas R, et al. (1999) Multilineage potential of adult human mesenchymal stem cells. Science 284: 143-147. [Crossref]

2. Battula V, Bareiss Pm, Treml S, Conrad S, Albert I, at al. (2007) Human placenta and bone marrow derived MSC cultured in serum-free, b-FGF-containing medium express cell surface frizzled-9 and SSEA-4 and give rise to multilineage differentiation. Differentiation 75: 279-291

3. Zvaifler Nj, Marinova-Mutafchieva L, Adams G, Edwards Cj, Moss J, et al. (2000) Mesenchymal precursor cells in the blood of normal individuals. Arthritis Res 2: 477488. [Crossref]

4. Erices A, Conget P, Minguell JJ (2000) Mesenchymal progenitor cells in human umbilical cord blood. Br J Haematol 109: 235-242. [Crossref]

5. Morizono K, De Ugarte Da, Zhu M, Zuk P, Elbarbary A, et al. (2003) Multilineage cells from adipose tissue as gene delivery vehicles. Hum Gene Ther 14: 59-66. [Crossref]

6. Dimitrov R, Timeva T, Kyurkchiev D, Stamenova M, Shterev A, et al. (2008) Characterization of clonogenic stromal cells isolated from human endometrium. Reproduction 135: 551-558. [Crossref]

7. Seeberger KL, Dufour JM, Shapiro AM, Lakey JR, Rajotte RV, et al. (2006) Expansion of mesenchymal stem cells from human pancreatic ductal epithelium. Lab Invest 86 : 141-153. [Crossref]

8. Baertschiger Rm, Bosco D, Morel P, Serre-Beinier V, Berney T, et al. (2008) Mesenchymal stem cells derived from human exocrine pancreas express transcription factors implicated in beta-cell development. Pancreas 37: 75-84. [Crossref]

9. Dominici M, Le Blanc K, Mueller I, Slaper-Cortenbach I, Marini F, et al. (2006) Minimal criteria for defining multipotent mesenchymal stromal cells. The International 
Society for Cellular Therapy position statement. Cytotherapy 8: 315-317. [Crossref]

10. Herdrich BJ, Lind RC, Liechty KW (2008) Multipotent adult progenitor cells: their role in wound healing and the treatment of dermal wounds. Cytotherapy 10: 543-550. [Crossref]

11. Spees Jl, Whitney Mj, Sullivan De, Lasky Ja, Laboy M, et al. (2008) Bone marrow progenitor cells contribute to repair and remodeling of the lung and heart in a rat model of progressive pulmonary hypertension. FASEB J 22: 1226-1236. [Crossref]

12. Gabr Mm, Zakaria Mm, Refaie Af, Khater Sm, Ashamallah Sa, et al. (2014) Generation of insulin-producing cells from human bone marrow-derived mesenchymal stem cells: comparison of three differentiation protocols. Biomed Res Int: 832736. [Crossref]

13. Madec AM, Mallone R, Afonso G, Abou Mrad E, Mesnier A, et al. (2009) Mesenchymal stem cells protect NOD mice from diabetes by inducing regulatory T cells. Diabetologia 52: 1391-1399. [Crossref]

14. Jurewicz M, Yang S, Augello A, Godwin Jg, Moore Rf, et al. Congenic mesenchymal stem cell therapy reverses hyperglycemia in experimental type 1 diabetes. Diabetes 59: 3139-3147.

15. Gerdoni E, Gallo B, Casazza S, Musio S, Bonanni I, et al. (2007) Mesenchymal stem cells effectively modulate pathogenic immune response in experimental autoimmune encephalomyelitis. Ann Neurol 61: 219-227. [Crossref]

16. Bocelli-Tyndall C, Bracci L, Spagnoli G, Braccini A, Bouchenaki M, et al. (2007) Bone marrow mesenchymal stromal cells (BM-MSCs) from healthy donors and auto-immune disease patients reduce the proliferation of autologous- and allogeneicstimulated lymphocytes in vitro. Rheumatology (Oxford) 46: 403-408. [Crossref]

17. Cahill Ra, Jones Oy, Klemperer M, Steele A, Mueller To, et al. (2004) Replacement of recipient stromal/mesenchymal cells after bone marrow transplantation using bone fragments and cultured osteoblast-like cells. Biol Blood Marrow Transplant 10: 709717. [Crossref]

18. Sanberg PR, Willing AE, Garbuzova-Davis S, Saporta S, Liu G, et al. (2005) Umbilical cord blood-derived stem cells and brain repair. Ann N Y Acad Sci 1049: 67-83. [Crossref]

19. Mahmood A, Lu D, Chopp M (2004) Intravenous administration of marrow stromal cells (MSCs) increases the expression of growth factors in rat brain after traumatic brain injury. J Neurotrauma 21: 33-39. [Crossref]

20. Iwamoto S, Mihara K, Downing JR, Pui CH, Campana D, et al. (2007) Mesenchymal cells regulate the response of acute lymphoblastic leukemia cells to asparaginase. J Clin Invest 117: 1049-1057. [Crossref]

21. Najar M, Raicevic G, Boufker Hi, Fayyad-Kazan H, De Bruyn C, et al. (2010) Adiposetissue-derived and Wharton's jelly-derived mesenchymal stromal cells suppress lymphocyte responses by secreting leukemia inhibitory factor. Tissue Eng Part A 16: 3537-3546. [Crossref]

22. Corritore E, Dugnani E, Pasquale V, Misawa R, Witkowski P, et al. (2014) $\hat{I}^{2}$-Cell differentiation of human pancreatic duct-derived cells after in vitro expansion. Cell Reprogram 16: 456-466. [Crossref]

23. Sordi V, Melzi R, Mercalli A, Formicola R, Doglioni C, et al. (2010) Mesenchyma cells appearing in pancreatic tissue culture are bone marrow-derived stem cells with the capacity to improve transplanted islet function. Stem Cells 28: 140-151. [Crossref]

24. Lima Mj, Muir Kr, Docherty Hm, Drummond R, Mcgowan Nw, et al. (2013) Suppression of epithelial-to-mesenchymal transitioning enhances ex vivo reprogramming of human exocrine pancreatic tissue toward functional insulin-producing beta-like cells. Diabetes 62: 2821-2833. [Crossref]

25. Song G, Habibovic P, Bao C, Hu J, Van Blitterswijk Ca, et al. (2013) The homing of bone marrow MSCs to non-osseous sites for ectopic bone formation induced by osteoinductive calcium phosphate. Biomaterials 34: 2167-2176. [Crossref]

26. Son Br, Marquez-Curtis La, Kucia M, Wysoczynski M, Turner Ar, et al. (2006) Migration of bone marrow and cord blood mesenchymal stem cells in vitro is regulated by stromal-derived factor-1-CXCR4 and hepatocyte growth factor-c-met axes and involves matrix metalloproteinases. Stem Cells 24: 1254-1264. [Crossref]

27. Sordi V, Malosio Ml, Marchesi F, Mercalli A, Melzi R, et al. (2005) Bone marrow mesenchymal stem cells express a restricted set of functionally active chemokine receptors capable of promoting migration to pancreatic islets. Blood 106: 419-427. [Crossref]

28. Lechner A, Yang YG, Blacken RA, Wang L, Nolan AL, et al. (2004) No evidence for significant transdifferentiation of bone marrow into pancreatic beta-cells in vivo. Diabetes 53: 616-623. [Crossref]

29. De Waele E, Wauters E, Ling Z, Bouwens L (2014) Conversion of human pancreatic acinar cells toward a ductal-mesenchymal phenotype and the role of transforming growth factor beta and activin signaling. Pancreas 43: 1083-1092. [Crossref]

30. Duband Jl, Monier F, Delannet M, Newgreen D (1995) Epithelium-mesenchyme transition during neural crest development. Acta Anat (Basel) 154: 63-78. [Crossref]

31. Tucker RP (2004) Neural crest cells: a model for invasive behavior. Int J Biochem Cell Biol 36: 173-177. [Crossref]

32. Thiery Jp, Sleeman Jp (2006) Complex networks orchestrate epithelial-mesenchymal transitions. Nat Rev Mol Cell Biol 7: 131-142.

33. Zhang L, Hong Tp, Hu J, Liu Yn, Wu Yh, et al. (2005) Nestin-positive progenitor cells isolated from human fetal pancreas have phenotypic markers identical to mesenchymal stem cells. World J Gastroenterol 11:2906-2911.

34. Hu Y, Liao L, Wang Q, Ma L, Ma G, et al. (2003) Isolation and identification of mesenchymal stem cells from human fetal pancreas. J Lab Clin Med 141: 342-349. [Crossref]

35. Eberhardt M, Salmon P, Von Mach Ma, Hengstler Jg, Brulport M, et al. (2006) Multipotential nestin and Isl-1 positive mesenchymal stem cells isolated from human pancreatic islets. Biochem Biophys Res Commun 345: 1167-1176. [Crossref]

36. Gershengorn Mc, Hardikar Aa, Wei C, Geras-Raaka E, Marcus-Samuels B, et al. (2004) Epithelial-to-mesenchymal transition generates proliferative human islet precursor cells. Science 306: 2261-4. [Crossref]

37. Joglekar MV, Joglekar VM, Joglekar SV, Hardikar AA (2009) Human fetal pancreatic insulin-producing cells proliferate in vitro. J Endocrinol 201: 27-36. [Crossref]

38. Gallo R, Gambelli F, Gava B, Sasdelli F, Tellone V, et al. (2007) Generation and expansion of multipotent mesenchymal progenitor cells from cultured human pancreatic islets. Cell Death Differ 14: 1860-1871.

39. Carlotti F, Zaldumbide A, Loomans CJ, van Rossenberg E, Engelse M, et al. (2010) Isolated human islets contain a distinct population of mesenchymal stem cells. Islets 2: 164-173. [Crossref]

40. Davani B, Ikonomou L, Raaka Bm, Geras-Raaka E, Morton Ra, et al. (2007) Human islet-derived precursor cells are mesenchymal stromal cells that differentiate and mature to hormone-expressing cells in vivo. Stem Cells 25: 3215-3222. [Crossref]

41. Russ HA, Bar Y, Ravassard P, Efrat S (2008) In vitro proliferation of cells derived from adult human beta-cells revealed by cell-lineage tracing. Diabetes 57: 1575-1583. [Crossref]

42. Russ Ha, Ravassard P, Kerr-Conte J, Pattou F, Efrat S, et al. (2009) Epithelialmesenchymal transition in cells expanded in vitro from lineage-traced adult human pancreatic beta cells. PLoS One 4: e6417.

43. Muir Kr, Lima Mj, Docherty Hm, Mcgowan Nw, Forbes S, et al. (2015) KruppelLike Factor 4 Overexpression Initiates a Mesenchymal-to-Epithelial Transition and Redifferentiation of Human Pancreatic Cells following Expansion in Long Term Adherent Culture. PLoS One 10: e0140352. [Crossref]

44. Atouf F, Park CH, Pechhold K, Ta M, Choi Y, et al. (2007) No evidence for mouse pancreatic beta-cell epithelial-mesenchymal transition in vitro. Diabetes 56: 699-702. [Crossref]

45. Chase LG, Ulloa-Montoya F, Kidder BL, Verfaillie CM (2007) Islet-derived fibroblastlike cells are not derived via epithelial-mesenchymal transition from Pdx-1 or insulinpositive cells. Diabetes 56: 3-7. [Crossref]

46. Morton Ra, Geras-Raaka E, Wilson Lm, Raaka Bm, Gershengorn Mc, et al. (2007) Endocrine precursor cells from mouse islets are not generated by epithelial-tomesenchymal transition of mature beta cells. Mol Cell Endocrinol 270: 87-93. [Crossref]

47. Shapiro Am, Lakey Jr, Ryan Ea, Korbutt Gs, Toth E, et al. (2000) Islet transplantation in seven patients with type 1 diabetes mellitus using a glucocorticoid-free immunosuppressive regimen. $N$ Engl J Med 343: 230-238. [Crossref]

48. Efrat S, Bar Y, Russ HA, Ramot At Tel-Aviv University Ltd (2014). Methods of expanding and redifferentiating islet beta cells. US Patent 8: 728-813.

49. Rukstalis Jm, Habener Jf (2007) Snail2 a mediator of epithelial-mesenchymal transitions, expressed in progenitor cells of the developing endocrine pancreas. Gene Expr Patterns 7: 471-479. [Cossref]

50. Gopurappilly R, Bhonde R (2015) Transcriptional profiling and functional network analyses of islet-like clusters (ILCs) generated from pancreatic stem cells in vitro. $\begin{array}{llll}\text { Genomics } & \text { 211-219. }\end{array}$ 
51. Iwano M, Plieth D, DanoffTM, Xue C, Okada H, et al. (2002) Evidence that fibroblast derive from epithelium during tissue fibrosis. $J$ Clin Invest 110: 341-350. [Crossref]
52. Alt E, Yan Y, Gehmert S, Song Y H, Altman, et al (2011) Fibroblasts share mesenchyma phenotypes with stem cells but lack their differentiation and colony-forming potential. Biol Cell 103: 197-208.
[Crossref] 